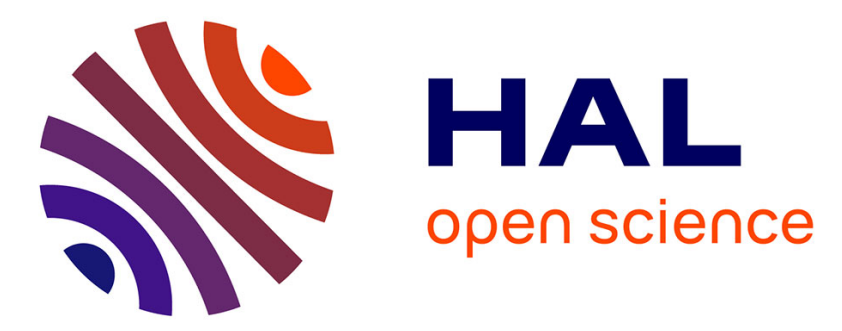

\title{
Measuring the burden of disease due to premature mortality using Standard Expected Years of Life Lost (SEYLL) in North Rhine-Westphalia, a Federal State of Germany, in 2005
}

Dietrich Penner, Paulo Pinheiro, Alexander Krämer

\section{To cite this version:}

Dietrich Penner, Paulo Pinheiro, Alexander Krämer. Measuring the burden of disease due to premature mortality using Standard Expected Years of Life Lost (SEYLL) in North Rhine-Westphalia, a Federal State of Germany, in 2005. Journal of Public Health, 2010, 18 (4), pp.319-325. 10.1007/s10389010-0322-1 . hal-00535310

\author{
HAL Id: hal-00535310 \\ https://hal.science/hal-00535310
}

Submitted on 11 Nov 2010

HAL is a multi-disciplinary open access archive for the deposit and dissemination of scientific research documents, whether they are published or not. The documents may come from teaching and research institutions in France or abroad, or from public or private research centers.
L'archive ouverte pluridisciplinaire HAL, est destinée au dépôt et à la diffusion de documents scientifiques de niveau recherche, publiés ou non, émanant des établissements d'enseignement et de recherche français ou étrangers, des laboratoires publics ou privés. 


\title{
Measuring the burden of disease due to premature mortality using Standard Expected Years of Life Lost (SEYLL) in North Rhine-Westphalia, a Federal State of Germany, in 2005
}

\author{
Dietrich Penner • Paulo Pinheiro • Alexander Krämer
}

Received: 1 October 2009 /Accepted: 25 February 2010/Published online: 18 March 2010

(C) Springer-Verlag 2010

\begin{abstract}
Aims and subjects Burden of disease (BoD) estimates are increasingly used in public health for assessing population health. Disability Adjusted Life Years (DALYs) - a summary measure frequently used in BoD studies - sum up the impact on health due to premature death and non-fatal health outcomes and allow for comprehensive and comparable assessments. To provide first estimates on the burden of disease in North RhineWestphalia (NRW), we calculated the burden due to premature death using Standard Expected Years of Life Lost (SEYLL), which is one of the two components of DALYs.

Materials and methods Methods provided by the World Health Organisation (WHO) and developed for the Global BoD (GBoD) study were used to estimate SEYLL in NRW in 2005. We used administrative death and cause of death statistics provided by local authorities.

Results In 2005, the total burden of disease due to premature death was $1,774,926$ SEYLLs. According to the GBoD disease categories, non-communicable (group II) diseases accounted for $89.1 \%$ of the burden. Communicable, maternal, perinatal and nutritional (group I) conditions contributed to $5.6 \%$ and injuries (group III conditions) to $5.3 \%$ of the total burden. The three leading single causes of the burden of disease due to premature death were ischaemic heart diseases, lung cancers and cerebrovascular diseases, together accounting for 558,785 SEYLLs (32\%).
\end{abstract}

\footnotetext{
D. Penner $(\bowtie) \cdot$ P. Pinheiro $\cdot$ A. Krämer

Department of Public Health Medicine, School of Public Health, University of Bielefeld,

Universitätsstraße 25,

33615 Bielefeld, Germany

e-mail: dietrich.penner@uni-bielefeld.de

P. Pinheiro

e-mail: paulo.pinheiro@uni-bielefeld.de

A. Krämer

e-mail: alexander.kraemer@uni-bielefeld.de
}

Conclusion First estimates of the burden of disease were feasible for NRW by use of WHO tools and administrative data. The findings of our study are consistent with WHO GBoD estimates and studies performed for other highincome countries. Our SEYLL results usefully complement the available health statistics highlighting diseases and injuries leading to death at an early age of life. However, our estimates are restricted to the impact of premature death and do not provide information on non-fatal health outcomes. Thus, future work should target estimates of the Years of Life Lost due to Disability (YLD) to provide a comprehensive assessment of the burden of disease in NRW.

Keywords Burden of disease $\cdot$ Mortality Population health Y Years of life lost · Disability adjusted life years

\section{Introduction}

Comprehensive and comparable data on the health status of a population are important for health policy decision-making processes. Although the amount and quality of health data have increased in the past, there are still difficulties in the handling of these quantitative datasets, especially for policy makers and researchers in Public Health (Boerma and Stansfield 2007). One frequent limitation of health information is the comparability of data, particularly with regard to different health states or diseases. Also, the global coverage of health data is distributed unequally with many, especially low-income countries lacking information on mortality in general and on a wide range of important diseases (Boerma and Stansfield 2007).

To approach this problem, the World Health Organisation (WHO), in cooperation with the World Bank and the Harvard School of Public Health, developed the Global Burden of Disease (GBoD) study in the late 1980s (Murray and Lopez 
1996). The main objective of the WHO GBoD Study was firstly to create a standardised framework for integrating all accessible information on mortality, causes of death, the individual health status and disease-specific epidemiology, and secondly to provide a comprehensive and comparable overview of the levels of population health and the causes of loss of health (Murray and Lopez 1996; Lopez et al. 2006). The GBoD estimates not only considered effects due to premature mortality, but also included the burden due to non-fatal health outcomes.

Summary Measures of Population Health (SMPH) are qualified for burden of disease estimates because they combine mortality and morbidity information and present the health state of a particular population as a single numerical index (Field and Gold 1998; Murray et al. 2002). One common SMPH is the Disability Adjusted Life Year (DALY), which was developed for the GBoD approach. The DALY measure provides estimates on the burden of disease by counting the years of healthy life lost in a population (Lopez et al. 2006; Murray and Lopez 1997). In particular, the DALY measure combines information on Years of Life Lost due to premature death (YLL) with information on Years of Life lost due to Disability (YLD) (Lopez et al. 2006; Reidpath et al. 2003; WHO 2008).

Since the first published results of the GBoD study (Murray and Lopez 1996), several other burden of disease studies have been conducted based on the WHO methodology, not only at the national but also at the local level (Michaud et al. 2006; Lozano et al. 2001; Mahapatra 2001; Dodhia and Philips 2008).

For Germany there is only sparse information on the burden of disease apart from the estimates that are available from the WHO GBoD project (Murray et al. 1994; Lopez et al. 2006). This contrasts with the fact that German health data are largely available, compared to many other countries with their own BoD estimates (Lozano et al. 1995; Naghavi et al. 2009). Therefore, the data situation in Germany should allow for more sophisticated burden of disease calculations. This paper provides first estimates on the burden of disease in North Rhine-Westphalia (NRW), which is a Federal State of Germany, using the WHO GBoD methodology. Here we present the results of the estimates on the burden due to premature death by calculating Standard Expected Years of Life Lost (SEYLL) for the year 2005 .

\section{Materials and methods}

\section{Population characteristics}

North Rhine-Westphalia (Nordrhein-Westfalen) is located in the Western part of Germany and accounts for about 17.9 million inhabitants, thus representing the most populous Federal State in Germany (IT NRW 2008). Sharing international boarders with Belgium and the Netherlands, NRW also shares national boarders with other German Federal States to the northern, eastern and southern parts. The Federal State of North Rhine-Westphalia was established by the British military administration in 1946 when Germany was fragmented after World War II.

Data SEYLL estimates use aggregated datasets and are calculated based on a standard life table (Model Life Table West Level 26). In this life table, the standard of life expectancy in optimal health at birth is set to 82.5 years for women and 80 years for men. These standard values were defined based on the highest observed life expectancy at the time the first GBoD study was developed (Japanese women 82.4) (Murray 1994; Murray and Lopez 1996; Begg et al. 2007). To calculate the SEYLLs at any age of life, every death that occurs before the ideal life expectancy is reached is defined as premature and is multiplied with the life expectancy at the age of death (Jamison et al. 2006; Murray and Lopez 1996).

For SEYLLs in our study, information on population, mortality and life expectancy data was needed. Population data were taken from the Institute for Information Technology in North Rhine-Westphalia (Infomationstechnologie Nordrhein-Westfalen). For mortality we used administrative data on mortality and causes of death for North RhineWestphalia for the year 2005 from the regional statistical and health authorities (Landesinstitut für Gesundheit und Arbeit (LIGA), Informationstechnologie NordrheinWestfalen (IT-NRW)). Additionally, we collected mortality and causes of death data for the year 2001 to allow for first comparisons over time for non-communicable diseases. LIGA provides aggregated datasets based on death certificates (Landesinstitut für Gesundheit und Arbeit des Landes Nordrhein-Westfalen 2008). The datasets are stratified by sex and age. Causes of death are classified according to the WHO International Classification three-digit system (10th revision; ICD 10; WHO 2007).

Conversion of data The calculation of the SEYLLs required a redistribution of our recorded data because of different age groups and a different disease classification system used by the WHO tools. For disease classification, WHO instruments use the Global Burden of Disease classification system with a tree structure and four levels of disaggregation including 108 conditions. At the first level of disaggregation there are three broad groups of disease entities:

(1) group 1 conditions: communicable, maternal, perinatal and nutritional conditions; (2) group 2 conditions: noncommunicable diseases; (3) group 3 conditions: injuries. 


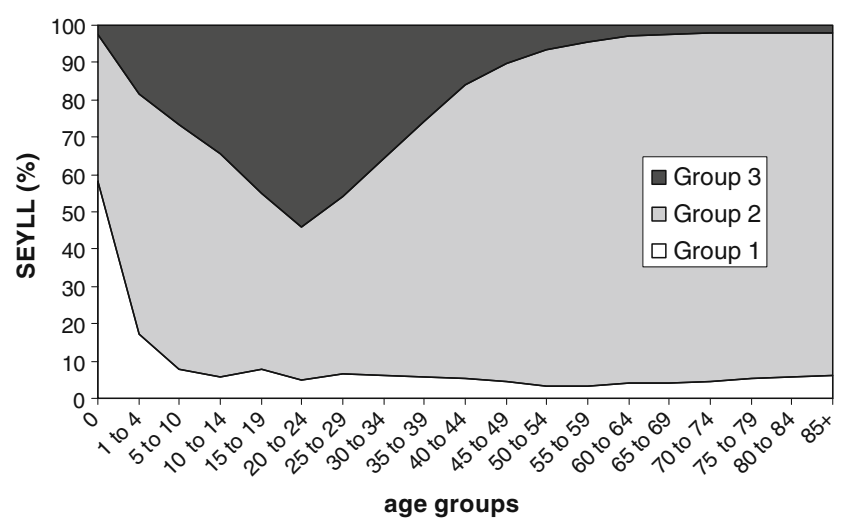

Fig. 1 Distribution of SEYLLs in NRW 2005 (both genders)

According to the WHO manual, the ICD coded data record was adjusted for the GBoD disease classification system and adopted according to the GBoD age groups (Lopez et al. 2006). The GBoD classification contains age groups starting with neonatal children and continuing with 5 -year age groups until the age of 85 years. People above the age of 85 are combined in the $85+$ group.

Use of WHO templates For calculation of estimates on SEYLLs due to premature mortality, the WHO presents three different templates (WHO 2008). Aiming at consistency of the recorded dataset the first template ensures quality of age, gender and disease-specific conditions. Another important objective is the redistribution of ill-defined and other not specifically coded or even miscoded data to the 108 diseasespecific conditions of the $\mathrm{GBoD}$ tree structure. This is of high importance for information on cardiovascular diseases data, which have been demonstrated to be associated with a high proportion of misclassification (Lozano et al. 2001). The redistribution of the ill-defined conditions is described elsewhere (Mathers et al. 2001; WHO 2008). In a last step, the adjusted data record was used for calculating the age- and sex-specific SEYLLs. The template allows for SEYLL results both with and without a 3\% time discount rate. Futhermore, the calculations allow for SEYLL estimates with and without an age-weighting function. For the description of our results we used the $3 \%$ time discount and uniform age weighting scenario in order to make our results comparable to the findings of the GBoD study.

\section{Results}

Total burden of disease due to premature death

The total burden due to premature mortality for North Rhine-Westphalia with 3\% time discount and uniform ageweighting accounts for $1,744,926$ SEYLLs. Men and women contribute to $916,979(52.6 \%)$ and 827,947 (47.4\%) SEYLLs, respectively; 89.1\% (1,555,709 SEYLLs) of the burden was caused by group 2 conditions. The proportions of group 1 and group 3 conditions account for 5.6 and $5.3 \%$, respectively.

Figure 1 shows the distribution of the three main disease entities stratified by age groups for NRW; $58.1 \%(12,456$ SEYLLs) of neonatal children are mostly affected by group 1 conditions. The proportion decreases continuously with an increase in age until, at the age group of 10-14 years, the percentage of $5.6 \%$ (114,9 SEYLLs) is reached. After that, the percentage remains constant. The percentage of group 2 diseases increases in the population above the age group of 20-24 years and peaks at about $93.2 \%(209,286$ SEYLLs) in the age group of 65-69 years. For group 3 conditions, the proportion of SEYLLs increases beginning with the age group of 1-4 years and peaks with $54.1 \%(6,086$ SEYLLs) at the age group of 20-24 years. It then decreases in older ages with a minimum of $2 \%(4,833$ SEYLLs) at the age group of 75-79 years.

Group 1 conditions (communicable, maternal, perinatal and nutritional conditions) The total burden due to communicable diseases was 97,056 SEYLLs (5.6\%). Lower respiratory infections caused the major burden of group 1 conditions with 39,218 SEYLLs (40.4\%), followed by low birth weight and diarrhoeal diseases with 8,338 SEYLLs (8.6\%) and 3,956 SEYLLs (4.1\%), respectively (Table 1).

The female population is burdened by 47,693 SEYLLs (49.1\%) and the male population by 49,364 SEYLLs (50.9\%) due to group 1 diseases. Lower respiratory infections are the leading single cause of SEYLLs for both

Table 1 Leading causes of SEYLLs by communicable diseases (NRW 2005)

\begin{tabular}{lll}
\hline No. & $\begin{array}{l}\text { The ten leading causes of SEYLLs } \\
\text { because of group 1 conditions }\end{array}$ & Total \\
\hline 1. & Lower respiratory infections & $39,218.59$ \\
2. & Low birth weight & $8,338.96$ \\
3. & Diarrhoeal diseases & $3,956.11$ \\
4. & Hepatitis B & $3,440.18$ \\
5. & Hepatitis C & $3,069.47$ \\
6. & HIV/AIDS & $2,552.03$ \\
7. & Meningitis & $1,319.70$ \\
8. & Birth asphyxia and birth trauma & $1,286.63$ \\
9. & Tuberculosis & 826.77 \\
10. & Iron-deficiency anaemia & 473.99 \\
\hline
\end{tabular}

*Other conditions: neoplasms, endocrine disorders, sense organ diseases, genitourinary diseases, skin diseases, musculoskeletal diseases, congenital anomalies, oral conditions, genitourinary diseases 
men and women, accounting for 18,598 SEYLLs (19.2\%) and 20,620 SEYLLs (21.2\%), respectively.

Group 2 conditions (non-communicable diseases) The overall disease burden due to group 2 conditions accounts for 1,555,709 SEYLLs (89.1\%). Cardiovascular diseases and malignant neoplasms are the leading disease entities and account for 653,398 SEYLLs (42\%) and 606,727 SEYLLs (39\%), respectively (Fig. 2).

Table 2 shows the SEYLL ranking of single group 2 conditions. Ischaemic heart disease is the leading single group 2 condition, accounting for 321,617 SEYLLs (20.7\%), followed by tracheal, broncheal and lung cancers, with cerebrovascular diseases adding another 131,529 SEYLLs (8.4\%) and 105,639 SEYLLs (6.8\%), respectively (Table 2).

The male population has a burden of 804,217 SEYLLs (51.7\%) and the female population of 751,492 SEYLLs (48.3\%) due to group 2 conditions. Both men and women are mostly affected by the impact of ischaemic heart disease with 182,777 (11.8\%) and 138,839 (8.9\%) SEYLLs, respectively.

SEYLL rates were also calculated for the group 2 conditions (Fig. 3). Therefore, the population of North Rhine-Westphalia stratified by age groups and sex for the year 2005 was taken as a denominator to calculate rates per 100,000 citizens. Figure 3 shows the distribution of SEYLLs caused by non-communicable diseases for the male and female population by age groups. The trend for the female population differs in the gradient of the rates. The gradient for the female population is lower but peaks at the age 85+ group with about 59,420 SEYLLs/100,000. Men in this age group demonstrate 50,335 SEYLLs/100,000.

Compared to the year 2005, the burden of disease due to premature death in 2001 accounted for 1,769,799 SEYLLs. SEYLL rates for group 2 conditions remained constant till

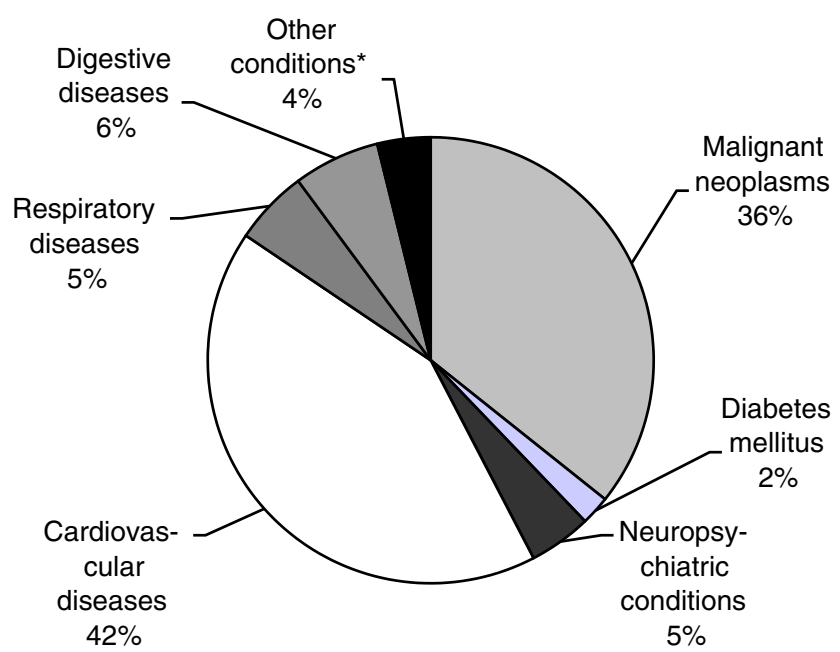

Fig. 2 SEYLLs caused by non-communicable diseases (NRW 2005; both genders)
Table 2 Top ten leading causes of SEYLLs by non-communicable diseases (NRW 2005)

\begin{tabular}{lll}
\hline No. & $\begin{array}{l}\text { The ten leading causes of SEYLLs } \\
\text { because of group 2 conditions }\end{array}$ & Total \\
\hline 1. & Ischaemic heart disease & $321,617.27$ \\
2. & Tracheal, broncheal, lung cancers & $131,529.35$ \\
3. & Cerebrovascular disease & $105,639.11$ \\
4. & Colon and rectum cancers & $70,878.60$ \\
5. & Breast cancer & $59,348.63$ \\
6. & Chronic obstructive pulmonary disease & $58,864.31$ \\
7. & Cirrhosis of the liver & $43,541.65$ \\
8. & Hypertensive heart disease & $38,850.47$ \\
9. & Diabetes mellitus & $33,083.27$ \\
10. & Stomach cancer & $28,411.21$ \\
\hline
\end{tabular}

the age of 44 years. For people above 70 years of age, the burden due to premature death in 2005 decreased compared to 2001 (Fig. 4).

Group 3 conditions (injuries) The burden of injuries accounts for 92,161 SEYLLs (5.3\%). Unintentional injuries and intentional injuries add 59,379 SEYLLs (64.4\%) and 32,782 SEYLLs $(35.6 \%)$ to the burden due to group 3 conditions, respectively. Self-inflicted injuries with 30,930 SEYLLs (33.6\%), road traffic accidents with 18,741 SEYLLs (20.3\%) and falls with 15,357 SEYLLs (16.7\%) cause the major burden due to injuries.

Men have a burden of 63,398 SEYLLs $(68.8 \%)$ and women of 28,762 SEYLLs (31.2\%). Both men and women are highly affected by self-inflicted injuries with 22,792 SEYLLs (27.7\%) and 8,137 SEYLLs (8.8\%), respectively.

\section{Discussion}

The BoD approach is increasingly used in international public health for assessing a population's health status at national or local levels (Michaud et al. 2006; Lozano et al. 2001; Mahapatra 2001; Dodhia and Philips 2008). This is the first study to present the BoD due to premature death for NRW, a Federal State of Germany, by use of SEYLLs according to the methods developed by the WHO GBoD project.

SEYLLs are the component of the DALY measure that represent the mortality burden and are usually combined with the YLDs representing the burden due to non-fatal health outcomes. We calculated the SEYLL measure due to data availability and quality. SEYLLs are usually easier to estimate than YLDs because they mainly require cause of death statistics. For reasons of feasibility, we thus focused on SEYLL estimates in our study. 
Fig. 3 Comparison of rates for non-communicable diseases (male and female population, NRW 2005)

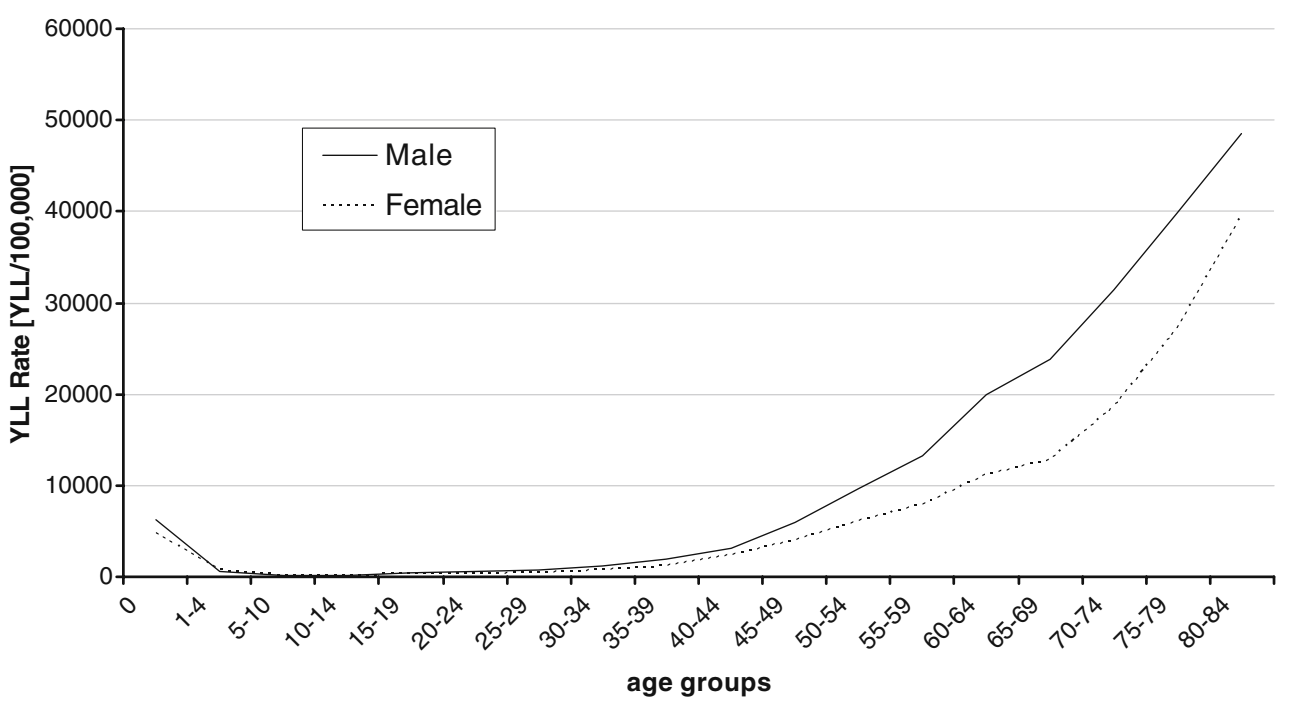

Our results are in good agreement with other findings from WHO GBoD studies for high-income countries where non-communicable diseases are the predominant group of diseases contributing to the burden of disease. For NRW, we estimated a proportion of $89.1 \%$ of the total SEYLL burden in 2005, which is in good agreement with Michaud et al. who reported a proportion of $80 \%$ of DALYs for group 2 conditions in the USA. As in other high-income countries, most of the SEYLL burden in NRW was caused by cardiovascular diseases and malignant neoplasms with $42 \%$ and $39 \%$, respectively. We identified ischaemic heart disease as the leading single condition contributing to the SEYLLs for both men and women. Similar patterns were reported for the USA (Michaud et al. 2006) and in other high-income countries (Murray et al. 2001).

Group 1 (communicable, maternal, perinatal and nutritional) conditions caused a seemingly negligible burden with $5.6 \%$ of the total SEYLLs in NRW, but should not be taken out of consideration because they affect especially children and young adults.
Injuries (group 3 conditions) contributed to $5.3 \%$ of the total SEYLLs in our estimates, with self-inflicted injuries being the leading single cause within this group of conditions. Like for group 1 and 2 conditions, our estimates are similar to findings from the GBoD study for the European region (Murray et al. 2001).

A considerable limitation of the exclusive use of SEYLLs for BoD assessments is the fact that non-fatal health outcomes with a high prevalence in a population are not represented, e.g., unipolar depressive or alcohol use disorders. SEYLLs use cause of death statistics and, in contrast to studies using Disability Adjusted Life Years, do not include any information on non-fatal health outcomes.

Compared to causes of death statistics using death numbers, the use of SEYLLs results in a different description of population health. In burden of disease studies health losses are counted in years of life and therefore highlight diseases and injuries leading to death at an early age of life. For instance, in our study we identified self-inflicted injuries to be among the ten most common single health conditions
Fig. 4 Comparison of rates for non-communicable disease (NRW 2001 vs. 2005)

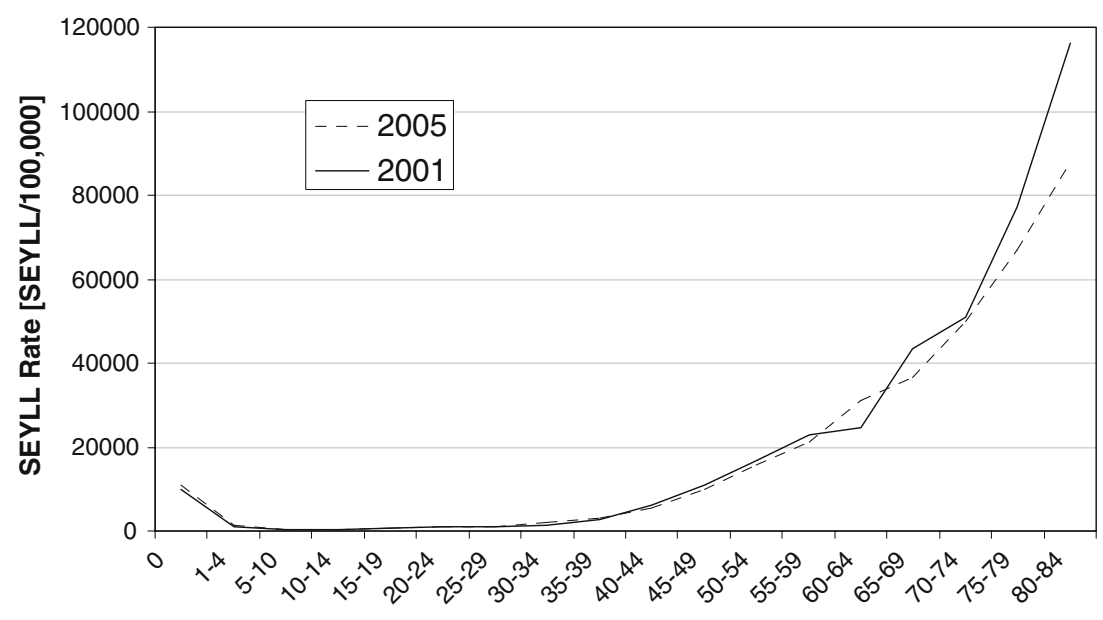

age groups 
contributing to the male burden of disease in NRW. When using death numbers, the ranking is considerably differant, with self-inflicted injuries only ranking at the 18th place. For women, similar observations can be made. Many studies have concluded that the SEYLL is a more comprehensive measure of the impact of premature death on health than measures such as death counts or death rates (Mariotti et al. 2003; Vlajinac et al. 2008). The use of the SEYLL measure gives a higher weight to conditions that affect young people than to conditions affecting older people (Vlajinac et al. 2008; Mariotti et al. 2003).

There are several possibilities to measure Years of Life Lost, depending on the health goal to which the losses are referred. Potential Years of Life Lost (PYLL), e.g., is an alternative measure that is used by the regional health authorities in NRW (LIGA 2005) for estimating the burden of disease due to premature death. The PYLL measure in NRW sets a fixed limit to life expectancy at 65 years of age, and thus does not take into account any deaths occurring beyond this threshold. In conclusion, PYLLs do not assess any burden of premature mortality for the age groups above 65 years of age, and so any health benefits to people in a later stage of life are not assessed when using PYLLs. In contrast, the SEYLL approach uses the remaining life expectancy at any age of life as reference, and thus every event of death contributes to the burden.

This study has shown that burden of disease estimates based on the WHO GBoD methodology is feasible at a local level. Furthermore, we believe that our SEYLL estimates complement the available health statistics for describing the health status of the NRW population in a very useful manner. However, our findings are limited to mortality and do not provide any information on the burden due to non-fatal health outcomes. In the future, we therefore aim at to calculate the Years of Life lost due to Disability (YLD) in order to include the impact of non-fatal health outcomes into our burden of disease estimates. Information on incidence, duration of disease and disability weights is needed to perform YLD calculations and thus to allow for a comprehensive assessment of the burden of disease in NRW by use of the DALY measure.

Conflict of interest The authors confirm that there are no relevant associations that might pose a conflict of interest.

Funding The study did not receive any funding.

\section{References}

Begg S, Voss T, Barker B, Stevenson C, Stanley L, Lopez AD (2007) Burden of Disease and Injury Australia 2003. Australian Institute of Health and Welfare; Canberra, School of Public Health, University of Queensland, Brisbane
Boerma JT, Stansfield SK (2007) Health statistics now: are we making the right investments? The Lancet Vol 369:779-786. doi:10.1016/S0140-6736(07)60364-X

Dodhia H, Philips K (2008) Measuring burden of disease in two inner London boroughs using Disability Adjusted Life Years. Journal of Public Health; p 1-9; Univesity Press Oxford. doi:10.1093/ pubmed/fdn015

Field MJ, Gold MR (1998) Summarizing population healthdirections for the development and application of population metrics. National Academy Press, Washington DC

IT NRW (2008) NRW-Einwohnerzahl rückläufig; Pressemitteilung, Düsseldorf http://www.it.nrw.de/presse/pressemitteilungen/2008/ pres_194_08.html Accessed 28 August 2009

Jamison DT, Breman JG, Measham AR, Alleyne G, Claeson M, Evans DB, Jha P, Mills A, Musgrove P (2006) Disease control priorities in developing countries (Second Edition). University Press, Oxford and The World Bank

Landesamt für Datenverarbeitung und Statistik NRW (2005) Bevölkerung nach Alter und Geschlecht, Nordrhein-Westfalen, 2005

Landesinstitut für Gesundheit und Arbeit des Landes Nordrhein-Westfalen (2005) Anzahl der durch Tod vor Vollendung des 65. Lebensjahres verlorenen Lebensjahre (PYLL) nach Todesursachen und Geschlecht, Nordrhein-Westfalen; http://www.liga.nrw.de/00indi/0data/ 03/html/0301200052005.html Accessed 28 August 2009

Landesinstitut für Gesundheit und Arbeit des Landes NordrheinWestfalen (2008) Daten für die Gesundheitsberichterstattung in NRW; Todesursachenstatistik nach ICD 10, LIGA NRW

Lopez AD, Mathers CD, Ezzati M, Jamison DT, Murray CJL (2006) Global burden of disease and risk factors. University Press, Oxford

Lozano R, Murray CJL, Frenk J, Bobadilla JL (1995) Burden of disease assessment and health system reform: results of a study in Mexico. J Int Dev 7:555-563. doi:10.1002/jid.3380070314

Lozano R, Murray CJL, Lopez AD, Satoh T (2001) Miscoding and misclassification of ischaemic heart disease mortality. World Health Organisation, Geneva

Mahapatra P (2001) Estimating national burden of disease: sensitivity to local data; the burden of disease in Andhra Pradesh, 1999. Institute of Health Systems, Hyderabad, India

Mariotti S, D'Errigo P, Mastroeni S, Freeman K (2003) Years of life lost due to premature mortality in Italy. Eur J Epidemiol 18:513521. doi:10.1023/A:1024635401206

Mathers C, Lopez AD, Salomon JA, Ezzati M (2001) National burden of disease studies: a practical guide. World Health Organisation, Geneva

Michaud C, McKenna M, Begg S, Tomijima N, Majmudar M, Bulzacchelli M, Ebrahim S, Ezzati M, Salomon J, Gaber Kreiser J, Hogan M, Murray C (2006) The burden of disease and injury in the United States; Population Health Metrics, Vol. 4. doi:10.1186/1478-7954-4-11

Murray CJL (1994) Quantifying the burden of disease: the technical basis for disability-adjusted life years. Bulletin of the World Health Organisation, 1994 72(3) p 429-445

Murray CJL, Lopez AD (1996) The global burden of disease. Harvard School of Public Health, Cambridge

Murray CJL, Lopez AD (1997) The utility of DALYs for public health policy and research: a reply. Bulletin of the World Health Organisation; 1997; 75(4) p 377-381

Murray CJL, Lopez AD, Jamison, DT (1994) The global burden of disease in 1990: summary results, sensitivity analysis and future directions. Bulletin of the World Health Organisation, 199472 (3); p 495-509

Murray CJL, Lopez AD, Mathers CD, Stein C (2001) The global burden of disease 2000 project: aims, methods and data resources; global programme on evidence for health policy discussion paper no. 36. World Health Organisation, Geneva 
Murray CJL, Salomon JA, Mathers CD, Lopez AD (2002) Summary measures of population health: concepts, ethics, measurement and applications. World Health Organization, Geneva

Naghavi M, Abolhassani F, Pourmalek F, Maziar M, Jafari N, Vaseghi S, Mahdavi Hezaveh NM, Kazemeini H (2009) The burden of disease and injury in Iran 2003; Population Health Metrics 2009; Vol. 7. doi:10.1186/1478-7954-7-9

Reidpath DD, Allotey PA, Kouame A, Cummins RA (2003) Measuring health in a vacuum: examining the disability weight of the DALY. Health Policy Plan 18(4):351-356. doi:10.1093/ heapol/czg043
Vlajinac H, Marinkovic J, Kocev N, Sipetic S, Bjegovic V, Jankovic S, Stanisavljevic D, Markovic-Denic L, Maksimovic J (2008) Years of life lost due to premature death in Serbia (excluding Kosovo and Metohia). J Pub Health 122:277-248. doi:10.1016/j. puhe.2007.06.010

WHO (2007) International statistical classification of diseases and related health problems 10th revision version for 2007. World Health Organisation, Geneva, http://apps.who.int/classifications/ apps/icd/icd10online/ Accessed 28 August 2009

WHO (2008) The global burden of disease: 2004 update. World Health Organisation, Geneva 